\title{
COMPARISONS OF THE FOVEAE DORSALES IN MALE AND FEMALE IXODID TICKS AMBLYOMMA AMERICANUM, A. MACULATUM, DERMACENTOR ANDERSONI AND D. VARIABILIS (ACARI: IXODIDAE) ${ }^{1}$
}

\author{
By R. C. Axtell and A. LeFurgey ${ }^{2}$
}

\begin{abstract}
The presence of foveae dorsales and underlying foveal glands was documented in the adult males and compared to those in the females of Amblyomma americanum, A. maculatum, Dermacentor andersoni and D. variabilis. Externally the male foveae dorsales were smaller and had fewer slits than the female glands, but internally there were no obvious gross differences between the sexes in the foveal glands.
\end{abstract}

Several species of ixodid ticks have been shown behaviorally to possess a sex pheromone produced by the female and attractive to the males (Berger et al. 1971, Sonenshine et al. 1974). In the case of 1 species, Amblyomma maculatum Koch, there is evidence of production of a pheromone by the males, since the females are attracted to the males (Gladney 1971, Gladney \& Drummond 1970a, b, Gladney et al. 1974a, b). The female-produced sex pheromone in Amblyomma americanum (L.), Dermacentor andersoni (Stiles) and D. variabilis (Say) is 2,6dichlorophenol (Berger 1972, Sonenshine et al. 1976). The source of the sex pheromone in adult female $D$. andersoni and $D$. variabilis is the foveal glands beneath the foveae dorsales. These glands were first described and their function elucidated by Sonenshine and co-workers (Layton \& Sonenshine 1975, Sonenshine et al. 1977, Vernick et al. 1978).

The foveae dorsales are paired, consist of a group of external openings (slits) and are located on the dorsal integument usually near the midline and in an area opposite approximately the midpoint between the $3 \mathrm{rd}$ and 4 th coxae. However, due to their small size, the foveae dorsales are difficult to find in the female tick with the aid of light

\footnotetext{
${ }^{1}$ Paper No. 5787 of the Journal Series of the North Carolina Agricultural Experiment Station, Raleigh, NC.

${ }^{2}$ Professor and Research Associate, respectively, Dep. of Entomology, North Carolina State University, Raleigh, NC 27650 , USA.
}

microscopy. In the male tick the foveae dorsales are even smaller and extremely difficult to locate even with scanning electron microscopy (SEM). Consequently, there have been considerable inadequacies in published reports as to whether or not the males possess foveae dorsales. Generally comprehensive publications on tick systematics and morphology have mentioned or labeled foveae dorsales in simple diagrammatic drawings of the males as well as the females, often with the incorrect assumption that they were sense organs (Arthur 1960, 1961, Cooley 1938, Dinnik \& Zumpt 1949, Douglas 1943, Hooker et al. 1912, Nuttall \& Warburton 1911, Robinson 1926, Salmon \& Stiles 1901, Schulze 1942). Balashov (1968) mentioned foveae dorsales only in the females. With only the light microscope available, it is questionable whether these reports were based on observations of the foveae dorsales or some other integumental lightdiffracting areas in the male ticks. Layton \& Sonenshine (1975) were unable to find the foveae dorsales in males of $D$. andersoni and $D$. variabilis. Subsequently, Sonenshine (pers. commun.) reported finding them. In A. americanum and A. maculatum the foveal glands have not been investigated. However, Gladney (pers. commun.) observed what were likely foveae dorsales in the male $A$. maculatum. With the dramatic progress in research on the sex pheromone and behavior of these species, there is a need for published illustrations and comparisons of the foveae dorsales in both sexes and these are presented herein.

\section{MATERIALS AND METHODS}

For scanning electron microscopy of the exterior structure of the foveae dorsales, unfed living adults of both sexes (10-26 specimens) of Amblyom- 
TABle 1. Comparison of foveae dorsales in $\delta$ and $q$ of 4 species of ixodid ticks.

\begin{tabular}{|c|c|c|c|}
\hline SEX & DIAM $(\mu \mathrm{m}) *$ & No. SLITS* & $\begin{array}{l}\text { SLIT LENGTH } \\
(\mu \mathrm{m})^{*}\end{array}$ \\
\hline \multicolumn{4}{|c|}{ Amblyomma americanum } \\
\hline$q$ & $36-78 \quad(56)$ & $10-30(15)$ & $2.4-7.1(5.1)$ \\
\hline$\sigma$ & $17-23 \quad(24)$ & $4-11(7)$ & $1.9-4.6(3.1)$ \\
\hline \multicolumn{4}{|c|}{ Amblyomma maculatum } \\
\hline$q$ & $45-84 \quad(66)$ & $25-28(26)$ & $3.8-6.0(5.0)$ \\
\hline$\delta$ & $\begin{aligned} 20-30 & \times 27-42 \\
(24 & \times 36)\end{aligned}$ & $10-21(16)$ & $2.8-5.2(3.8)$ \\
\hline \multicolumn{4}{|c|}{ Dermacentor andersoni } \\
\hline$q$ & $47-144(98)$ & $13-35(26)$ & $4.3-8.5(5.4)$ \\
\hline$\delta$ & $14-70 \quad(52)$ & $17-27(22)$ & $2.5-6.2(4.2)$ \\
\hline \multicolumn{4}{|c|}{ Dermacentor variabilis } \\
\hline$q$ & $81-112(97)$ & $19-26(22)$ & $4.3-7.1(5.4)$ \\
\hline$\delta$ & $33-50 \quad(41)$ & $6-13(12)$ & $2.9-5.8(4.6)$ \\
\hline
\end{tabular}

* Range (avg).

ma americanum, A. maculatum, Dermacentor andersoni, and $D$. variabilis were coated with carbon-gold/palladium and examined with an ETEC Autoscan scanning electron microscope at an operating voltage of $10 \mathrm{kV}$.

For scanning electron microscopy of the interior structure of the foveae dorsales, unfed living adults of both sexes were fixed $12-24 \mathrm{~h}$ in Na-cacodylate-buffered $5 \%$ glutaraldehyde at $4{ }^{\circ} \mathrm{C}$. Small slits were cut in the edge of the cuticle of all specimens to allow penetration of the glutaraldehyde into internal tissues. The whole ticks were then washed $12-24 \mathrm{~h}$ in Na-cacodylate buffer at $4{ }^{\circ} \mathrm{C}$, dehydrated in a graded ethanol series of $15 \%$ to $100 \%$, and sectioned through the foveae dorsales using a cryofracture technique adopted from Humphreys et al. (1974) and Lim (1971). A shallow aluminum dish containing a whole tick in $100 \%$ ethanol was placed on a liquid nitrogencooled brass block, and positioned for viewing under a stereomicroscope. Liquid nitrogen was gently poured around the dish and block so that the tick was frozen within the ethanol. The foveae dorsales remained visible through the frozen ethanol at $50 \times$ in all species (except $A$. americanum males, $100 \times)$, allowing horizontal or longitudinal fractures to be made through the foveae dorsales with a nitrogen-cooled single-edge razor blade. The sectioned tick and surrounding ethanol were allowed to thaw and the tick sections were then transferred to fresh $100 \%$ ethanol. The fractured segments were critical point-dried in freon-13 after intermediate replacement of the ethanol with freon-113 (Nemanic 1972). For observation in the ETEC
Autoscan the dried sections were mounted on aluminum stubs and coated with carbon-gold/palladium. Operating voltages were 5 to $15 \mathrm{kV}$.

\section{RESULTS}

External structure (FIG. 1-8)

In both females and males the foveae dorsales consist of paired depressions or pits, located at approximately $2 / 3$ the length of the body from the capitulum to the posterior edge and centered from side to side on the dorsum. In the female the foveae dorsales are on the extensible alloscutal area posterior to the nonextensible scutum, approximately over the genital pore, and at the level of the last pair of legs. In the male the foveae dorsales occur on the nonextensible dorsal area, posterior to the pseudoscutum, and also are centered at the level of the last pair of legs. A single large seta usually occurs near each pit in both males and females. The foveae dorsales are circular in all species examined except in the males of $\mathrm{A}$. maculatum, in which they are distinctly oval. In males of the 4 species the diameter of each fovea is smaller than in females (TABLE 1), in proportion to the smaller overall body dimensions for males as compared to females. The nonextensible cuticle of the male is similar in texture to and contiguous with the dorsal pit. Therefore, the foveae dorsales are not as evident in males as in females, in which the accordion folds of the extensible cuticle contrast sharply with the relatively smooth area of the pits and emphasize the slight depression of the pits below cuticular level (e.g., see Fig. 9b, 10b).

Except in $A$. americanum males, the depressions are visible under the dissecting microscope at $50 \times$ in both sexes of all species. The average diameter of a fovea in the A. americanum males examined was $24 \mu \mathrm{m}$, approximately $1 / 2$ the size of a fovea in Dermacentor males and $1 / 4$ to $1 / 2$ the size of a fovea in Dermacentor and Amblyomma females (TABLE 1). The depressions in A. americanum males, while difficult to locate initially, may be seen at $100 \times$.

With the scanning electron microscope, the structures within the depressions of either $\mathrm{Am}$ blyomma or Dermacentor specimens are clearly visible. In males and females of the 4 species examined, the depression is composed of irregularly arranged slits, varying in both length and number from species to species. The orientation of the slits is neither distinctly posterior-anterior nor distallateral; both directions and gradations from one to the other direction, occur within a single fovea. 


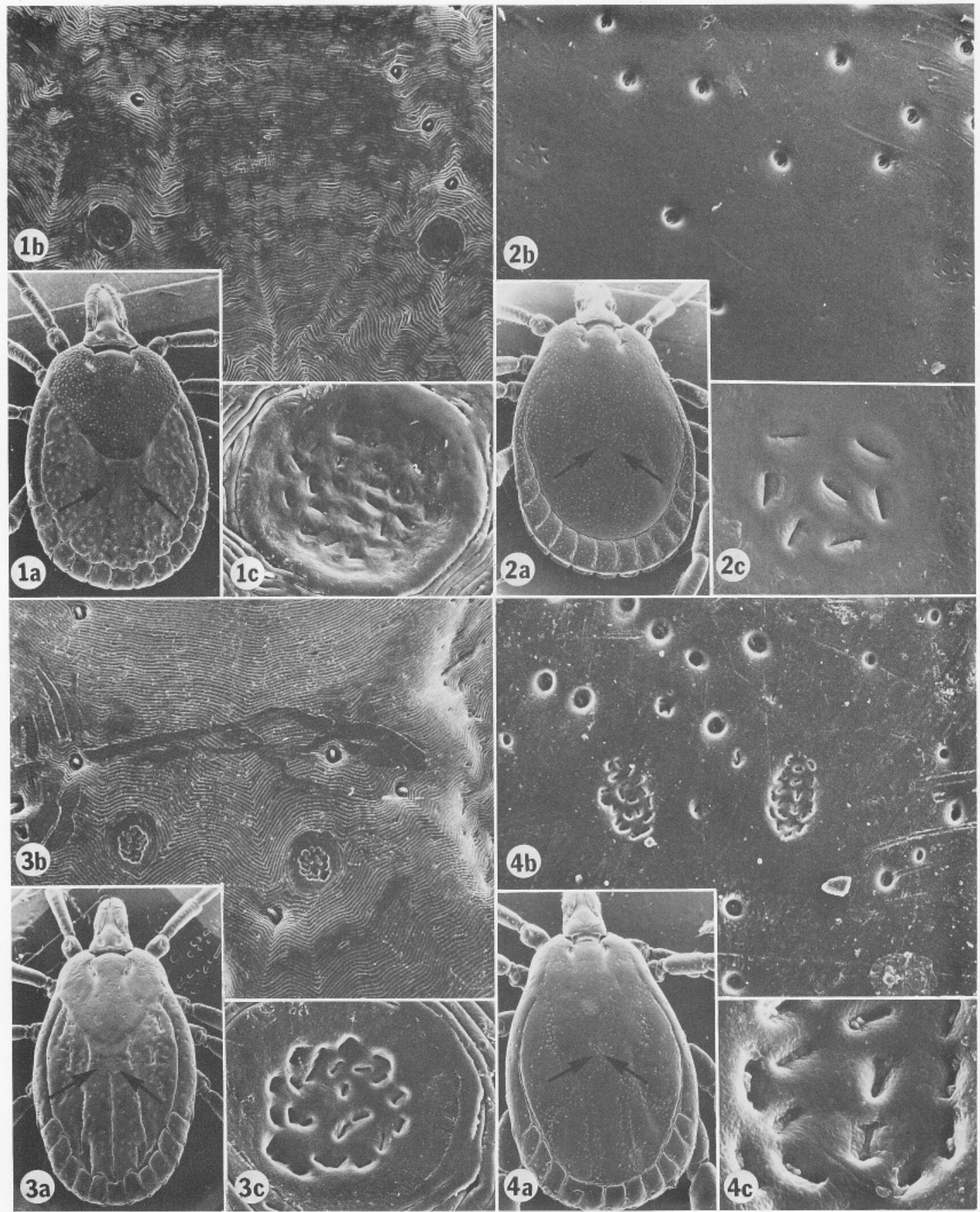

Fig. 1-4. 1. Adult 우 Amblyomma americanum. la, dorsal view showing locations of foveae dorsales (arrows) $(21 \times) .1 b$, closer view of the pair of foveae dorsales $(138 \times)$. lc, close-up of a fovea dorsales showing slit openings $(892 \times)$. 2. Adult o Amblyomma americanum. 2a, dorsal view showing locations of foveae dorsales (arrows) (19 $\times$ ). $2 \mathrm{~b}$, closer view of the pair of foveae dorsales $(441 \times)$. 2c, close-up of a fovea dorsales showing slit openings $(1582 \times)$. 3. Adult $\&$ Amblyomma maculatum. $3 \mathrm{a}$, dorsal view showing locations of foveae dorsales (arrows) (14×). $3 \mathrm{~b}$, closer view of the foveae dorsales $(170 \times)$. $3 \mathrm{c}$, close-up of a fovea dorsales showing slit openings $(741 \times)$. 4 . Adult $\delta$ Amblyomma maculatum. 4a, dorsal view showing locations of foveae dorsales (arrows) (17×). $4 \mathrm{~b}$, closer view of the foveae dorsales $(426 \times)$. $4 \mathrm{c}$, close-up of a fovea dorsales showing slit openings $(2130 \times)$. 


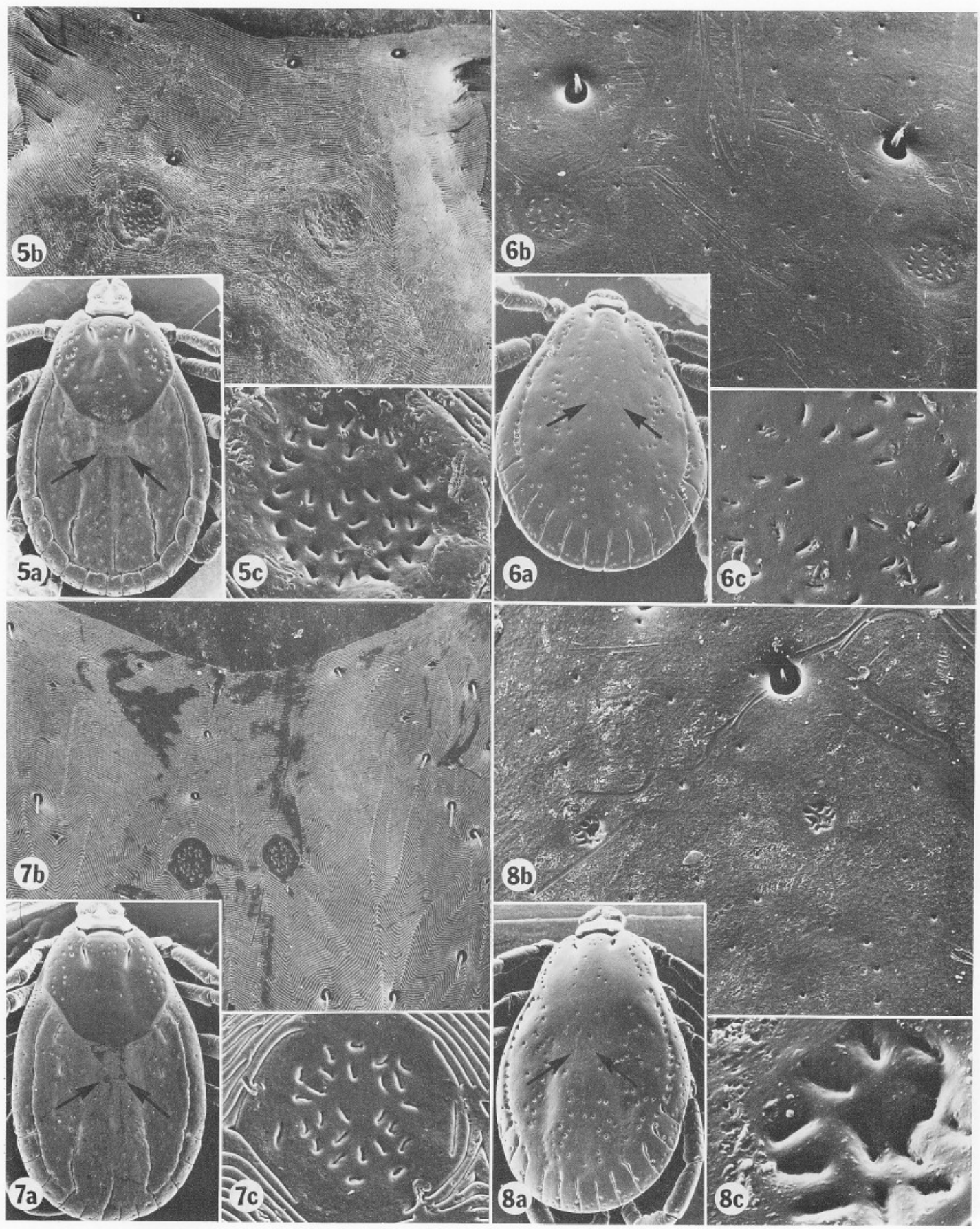

FIG. 5-8. 5. Adult $q$ Dermacentor andersoni. 5a, dorsal view showing locations of foveae dorsales (arrows) $(12 \times) .5$ b, closer view of the pair of foveae dorsales $(128 \times) .5 \mathrm{c}$, close-up of a fovea dorsales showing slit openings $(532 \times)$. 6. Adult $\delta$ Dermacentor andersoni. 6a, dorsal view showing locations of foveae dorsales (arrows) (12×). $6 \mathrm{~b}$, closer view of the pair of foveae dorsales $(210 \times) .6 \mathrm{c}$, close-up of a fovea dorsales showing slit openings $(532 \times)$. 7. Adult $\&$ Dermacentor variabilis. $7 \mathrm{a}$, dorsal view showing locations of foveae dorsales (arrows) (12×). $7 \mathrm{~b}$, closer view of the pair of foveae dorsales $(93 \times)$. $7 \mathrm{c}$, close-up of a fovea dorsales showing slit openings $(497 \times)$. 8. Adult of Dermacentor vanabilis. 8 a, dorsal view showing locations of foveae dorsales (arrows) (19 $\times$ ). 8 b, closer view of the pair of foveae dorsales $(93 \times) .8$ c, close-up of a fovea dorsales showing slit openings $(1849 \times)$. 
The average number of slits present in the males of each species, 7.3-21.7, is less than the average number of slits in the females of the same species, 15.3-26.5 (TABLE 1). Also, the length of the individual slit openings in the males of each species, averaging $3.1-4.6 \mu \mathrm{m}$, is less than in the corresponding females, 5.1-5.4 $\mu \mathrm{m}$ (TABLE 1). The narrow range of measurements in female slit lengths suggests that the slit length is constant from species to species.

\section{Internal structure (FIG. 9-11)}

Cryofractured sections through the foveae dorsales show similar morphologies for both sexes of the 4 species. The lobed gland previously described by Layton \& Sonenshine (1975) in females of $D$. andersoni and $D$. variabilis was observed in males of those species, as well as in both sexes of $A$. maculatum and $D$. andersoni. Due to the lack of standardization of the physiological state of our specimens and the variation in the appearance of the glands in different specimens, we cannot report any reliable observation on whether or not there was atrophy in the male glands. Comparison of photomicrographs of the males and females of the 4 species shows that the slits in the foveae dorsales of $A$. maculatum males externally resemble the slits of the female foveae dorsales more closely than do those of males and females of the other 3 species. Sections through the foveae dorsales revealed no obvious differences in the foveal glands and ducts of the male and female $A$. maculatum (Fig. 9, 10). In A. americanum, due to the small size and difficulty in locating the foveae dorsales, cryofractured sections were very poor and not illustrated, but we believe that we observed foveal glands. In both males and females of $D$. andersoni (FIG. 11) and D. variabilis (not illustrated), foveal glands were located in cryofractured sections. In our male specimens the lobes of the foveal glands appeared smaller and less swollen than in the females but this may have been due to the condition of the specimens or the preparation methods. In the females of $D$. andersoni, these glands have been well illustrated by Layton \& Sonenshine (1975), Sonenshine et al. (1977) and Vernick et al. (1978).

\section{DISCUSSION AND CONCLUSIONS}

Examinations with SEM of both sexes of $\mathrm{Am}$ blyomma americanum, A. maculatum, Dermacentor andersoni, and $D$. variabilis confirm the presence of foveae with similar slit openings in males as well as females. SEM views of sections through the foveae dorsales show that similar internal structures are present in males and females. Each slit opening within the fovea is the external termination of a duct which originates below the cuticle in the foveal gland. In the case of Dermacentor females, Sonenshine et al. (1977) demonstrated that the foveal gland is the site of sex pheromone production. The site of pheromone production in Amblyomma has not been demonstrated, but is assumed to be the foveal glands also. The fact that this gland also occurs in the males of Dermacentor and Amblyomma raises a question about the production of sex pheromone in the male. However, only trace amounts of pheromone (2,6-dichlorophenol) have been found in the males of $D$. andersoni and $D$. variabilis by Sonenshine \& Silverstein (Sonenshine, pers. commun.). Similarly, Kellum \& Berger (1977) found only trace amounts of 2,6-dichlorophenol in males of $A$. americanum but substantial quantities in the males of $A$. maculatum. The role of the glands in the male tick is obscure, since males are not known to release sex pheromone and metastriate females are not normally attracted to feeding metastriate males. In the exceptional case of $A$. maculatum, the unfed males as well as the unfed females are attracted to the feeding males and, consequently, this is more of an aggregation response than a sexual one (Gladney 1974b). Similarly, an assembly pheromone produced by fed male $A$. hebraeum Koch attracts both males and females (Rechav et al. 1977). Although 2,6-dichlorophenol is present in about equal amounts in both sexes of $A$. maculatum, apparently it is not the sex pheromone since the females do not exhibit a response to the chemical in behavioral experiments (Kellum \& Berger 1977; Gladney, pers. commun.).

An increase in size of the foveal gland in females with progressive feeding accompanies increased attractance of males to females of $D$. andersoni and D. variabilis (Layton \& Sonenshine 1975, Sonenshine et al. 1974). Apparently this does not occur in the males of those species and A. americanum, and presumably the male glands are nonfunctional (since only trace amounts of 2,6-dichlorophenol have been found in whole tick extracts). Our observations suggest that there may be atrophy of the glands in males of A. americanum, D. andersoni and $D$. variabilis but the variability in the physiological condition of the specimens and the possibility of preparation artifacts prevent a definite conclusion. It is also possible that the male glands produce some yet unidentified chemical during some por- 


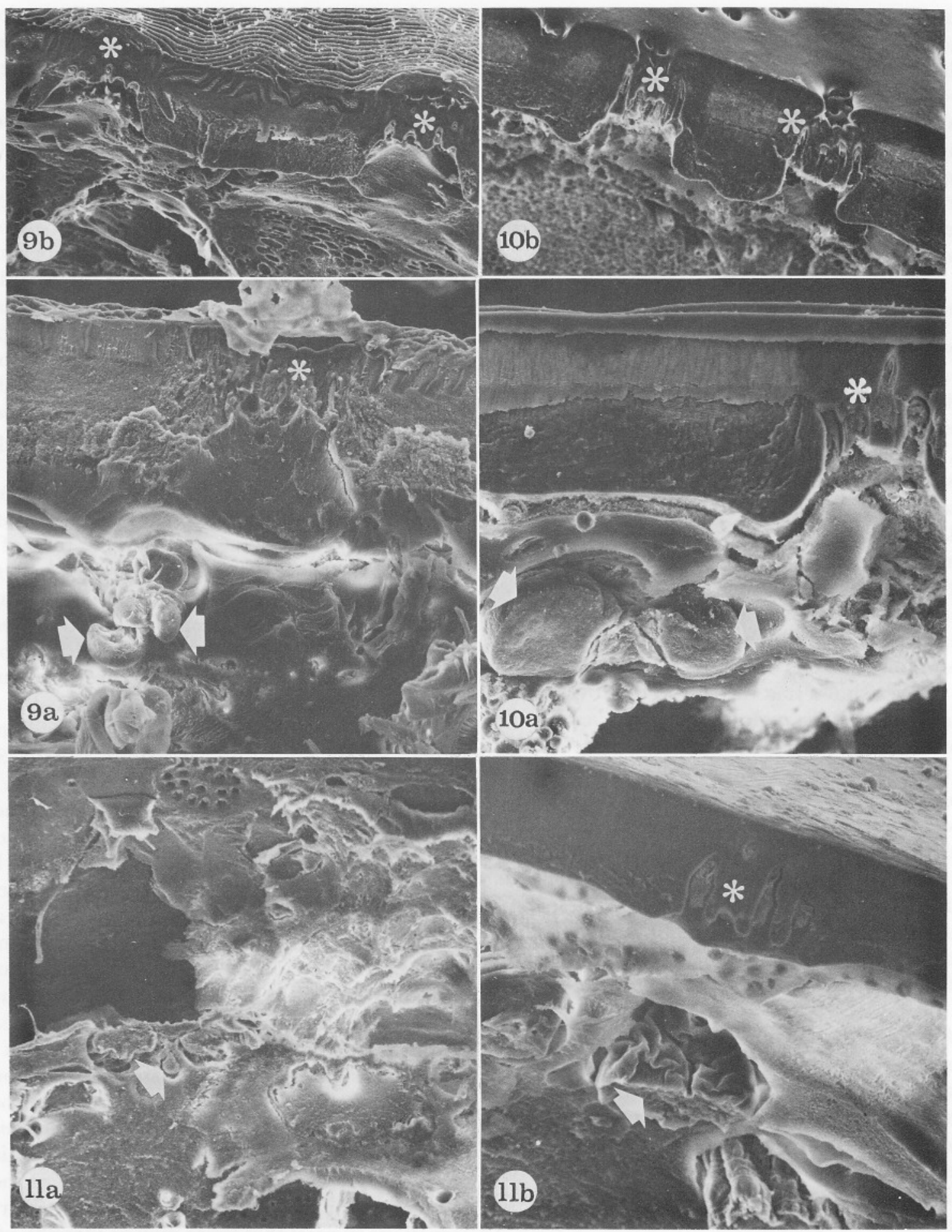

FIg. 9-11. 9a,b. Adult $\&$ Amblyomma maculatum: cryofractured section through the foveae dorsales showing foveal gland (arrows) and cuticular canals (*) leading to the exterior slit openings of the foveae dorsales. 10a,b. Adult $\delta$ Amblyomma maculatum: cryofractured section through the foveae dorsales showing foveal gland (arrows) and cuticular canals (*) leading to the exterior slit openings of the foveae dorsales. 11a,b. Adult $\delta^{*}$ Dermacentor andersoni: cryofractured section through the foveae dorsales showing foveal gland (arrows) and cuticular canals (*) leading to the exterior slit openings of the foveae dorsales. 
tion of the life of the tick. In A. maculatum males the foveal glands are obviously functional, since substantial amounts of 2,6-dichlorophenol have been found. Since this is not the pheromone attracting the female it is possible that some other chemical is produced by the male to attract the female, while 2,6-dichlorophenol aggregates the males. The complex behavior of these tick species, coupled with the knowledge that the foveae dorsales in males are apparently morphologically similar to the foveae dorsales in females, suggests the possibility that both sexes may produce foveal secretion(s) of varying nature and function (including defense) during various physiological states.

Our study of the gross external and internal morphology of the foveae dorsales reveals major similarities rather than differences among males and females of 4 tick species. However, examination of the foveae dorsales at the ultrastructural level is necessary to determine if the glands are indeed identically structured in all species. It may well be that the foveal glands in males of some species (A. americanum, D. andersoni and D. variabilis) function only at a much lower level than the glands in the females or even produce a different chemical, while in other species (A. maculatum) the male glands are very active.

Acknowledgments. We gratefully acknowledge the advice and suggestions from D. E. Sonenshine (who supplied specimens of Dermacentor andersoni and D. variabilis) and W. J. Gladney (who supplied specimens of Amblyomma americanum and A. maculatum).

\section{LITERATURE CITED}

Arthur, D. R. 1960. Ticks: A monograph of the Ixodoidea, Part V. On the genera Dermacentor, Anocentor, Cosiomma, Boophilus and Margaropus. Cambridge University Press, London. 251 p. 1961. Ticks and disease. Pergamon Press, Ltd., Edinburgh. $455 \mathrm{p}$.

Balashov, Y. S. 1968. Bloodsucking ticks (Ixodoidea): Vectors of diseases of man and animals. Misc. Publ. Entomol. Soc. Am. 8: 1-376.

Berger, R. S. 1972. 2,6-dichlorophenol sex pheromone of the Lone Star tick. Science 177: 704-05.

Berger, R. S., J. C. Dukes \& Y. S. Chow. 1971. Demonstration of a sex pheromone in three species of hard ticks. J. Med. Entomol. 8: 84-86.

Cooley, R. A. 1938. The genera Dermacentor and Otocentor (Ixodidae) in the United States, with studies in variation. Natl. Inst. Health Bull. 171: 1-90.

Dinnik, J. \& F. Zumpt. 1949. The integumentary sense organs of the larvae of Rhipicephalinae (Acarina). Psyche 56: 117.

Douglas, J. R. 1943. The internal anatomy of Dermacentor andersoni Stiles. Univ. Calif. Berkeley Publ. Entomol. 7: 207-71.

Gladney, W. J. 1971. Mate seeking by female Amblyomma maculatum (Acarina: Ixodidae) on a bovine. Nature, London 232: 401-02.

Gladney, W. J. \& R. O. Drummond. 1970a. Migration of male Lone Star ticks on the host in relation to mating. J. Econ. Entomol. 63: 1214-16. 1970b. Mating behavior and reproduction of the Lone Star tick, Amblyomma americanum. Ann. Entomol. Soc. Am. 63: $1036-39$.

Gladney, W. J., S. E. Ernst \& R. R. Grabbe. 1974a. The aggregation response of the Gulf Coast tick on cattle. Ann. Entomol. Soc. Am. 67: 750-52.

Gladney, W. J., R. R. Grabbe, S. E. Ernst \& D. D. Oehler. 1974b. The Gulf Coast tick: Evidence of a pheromone produced by males. J. Med. Entomol. 11: 303-06.

Hooker, W. A., F. C. Bishopp \& H. P. Wood. 1912. The life history and bionomics of some North American ticks. U.S. Dep. Agric. Bull. 106. 239 p.

Humphreys, W. J., B. O. Spurlock \& J. S. Johnson. 1974. Critical point drying of ethanol-infiltrated, cryofractured biological specimens of SEM. p. 275-82. In: Proc. 7 th Annu. Scanning Electron Microscopy Symp., Part I. IIT Research Institute, Chicago.

Kellum, D. \& R. S. Berger. 1977. Relationship of the occurrence and function of 2,6-dichlorophenol in two species of Amblyomma (Acari: Ixodidae). J. Med. Entomol. 13: 701-05.

Layton, E. C. \& D. E. Sonenshine. 1975. Description of a gland associated with the foveae dorsales in 2 species of Dermacentor ticks, and its possible role in sex pheromone activity (Metastigmata: Ixodidae). J. Med. Entomol. 12: 28795.

Lim, D. J. 1971. Scanning electron microscopic observations on non-mechanically cryofractured biological tissue. p. 257-64. In: Proc. 4th Annu. Scanning Electron Microscopy Symp., Part I. IIT Research Institute, Chicago.

Nemanic, M. K. 1972. Critical point drying, cryofracture, serial sectioning. p. 297-304. In: Proc. 5th Annu. Scanning Electron Microscopy Symp., Part II. IIT Research Institute, Chicago.

Nuttall, G. H. F. \& C. Warburton. 1911. p. 105-348. In: Ticks: A monograph of the Ixodoidea. Part II. Ixodidae. Cambridge University Press, London.

Rechav, Y., H. Parolis, G. B. Whitehead \& M. M. Knight. 1977. Evidence for an assembly pheromone(s) produced by males of the bont tick, Amblyomma hebraeum (Acarina: Ixodidae). J. Med. Entomol. 14: 71-78.

Robinson, L. E. 1926. p. 1-302. In: Ticks: A monograph of the Ixodoidea. Part IV. The genus Amblyomma. Cambridge University Press, London.

Salmon, E. C. \& C. W. Stiles. 1901. The cattle ticks (Ixodoidea) of the United States. p. 380-488. 17th Annu. Rep. (1900) Bur. Anim. Ind., Dep. Agric., Washington.

Schulze, P. 1942. Uber die Hautsinnesorgane der Zecken, besonders uber eine bisher unbekannte Art von Arthropoden-Sinnesorganen, die Krobylopheren. Z. Morphol. Oekol. Tiere 38: 379-419.

Sonenshine, D. E., R. M. Silverstein, L. A. Collins, M. Saunders, C. Flynt \& P. J. Homsher. 1977. The foveal glands: Source of sex pheromone in the ixodid tick, Dermacentor andersoni Stiles. J. Chem. Ecol. 3: 697-706.

Sonenshine, D. E., R. M. Silverstein, E. C. Layton \& P. J. Homsher. 1974. Evidence for the existence of a sex pheromone in 2 species of ixodid ticks (Metastigmata: Ixodidae). J. Med. Entomol. 11: 307-15.

Sonenshine, D. E., R. M. Silverstein, E. Plummer, J. R. West \& T. McCullough. 1976. 2,6-dichlorophenol, the sex pheromone of the Rocky Mountain wood tick, Dermacentor andersoni Stiles, and the American dog tick, Dermacentor variabilis (Say). J. Chem. Ecol. 2: 201-09.

Vernick, S. H., S. Thompson, D. E. Sonenshine, L. A. Collins, M. Saunders \& P. J. Homsher. 1978. Ultrastructure of foveal glands of ticks, Dermacentor andersoni Stiles and $D$. variabilis (Say). J. Parasitol. 64: 515-23. 